Supplement of Biogeosciences, 14, 2877-2889, 2017

https://doi.org/10.5194/bg-14-2877-2017-supplement

(C) Author(s) 2017. This work is distributed under

the Creative Commons Attribution 3.0 License.

(c) (1)

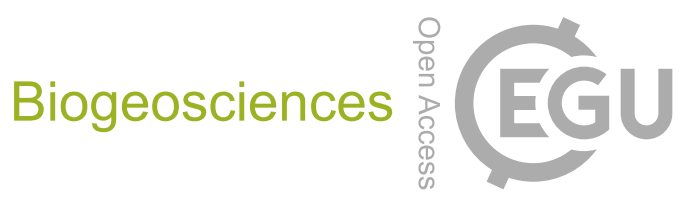

Supplement of

\title{
Biogeochemical versus ecological consequences of modeled ocean physics
}

Sophie Clayton et al.

Correspondence to: Sophie Clayton (sclayton@uw.edu)

The copyright of individual parts of the supplement might differ from the CC BY 3.0 License. 


\section{Supplementary Information}

We include in this supplement, several figures showing the output of the CR simulation not included in the main text.
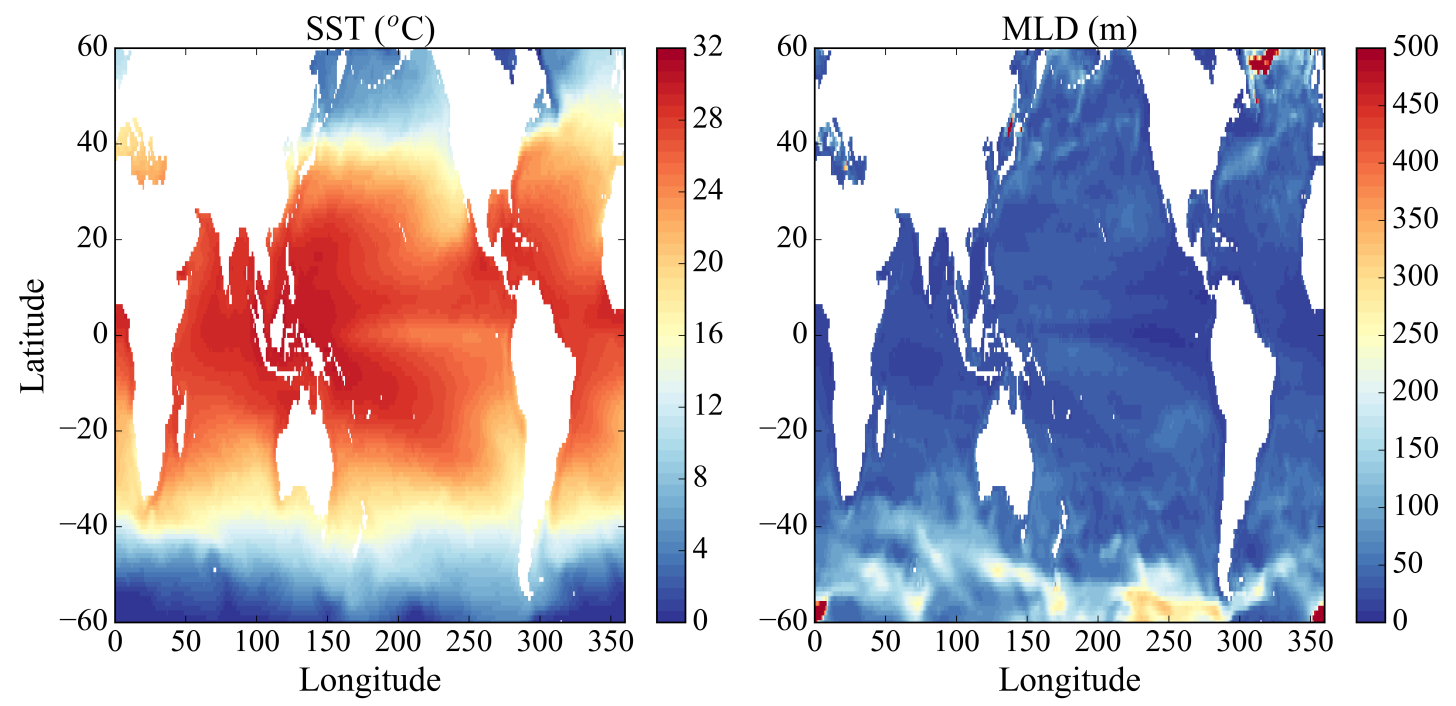

Figure S1. Annual average (a) sea surface temperature, and (b) mixed layer depths in the CR simulation for the 1999 model year. 

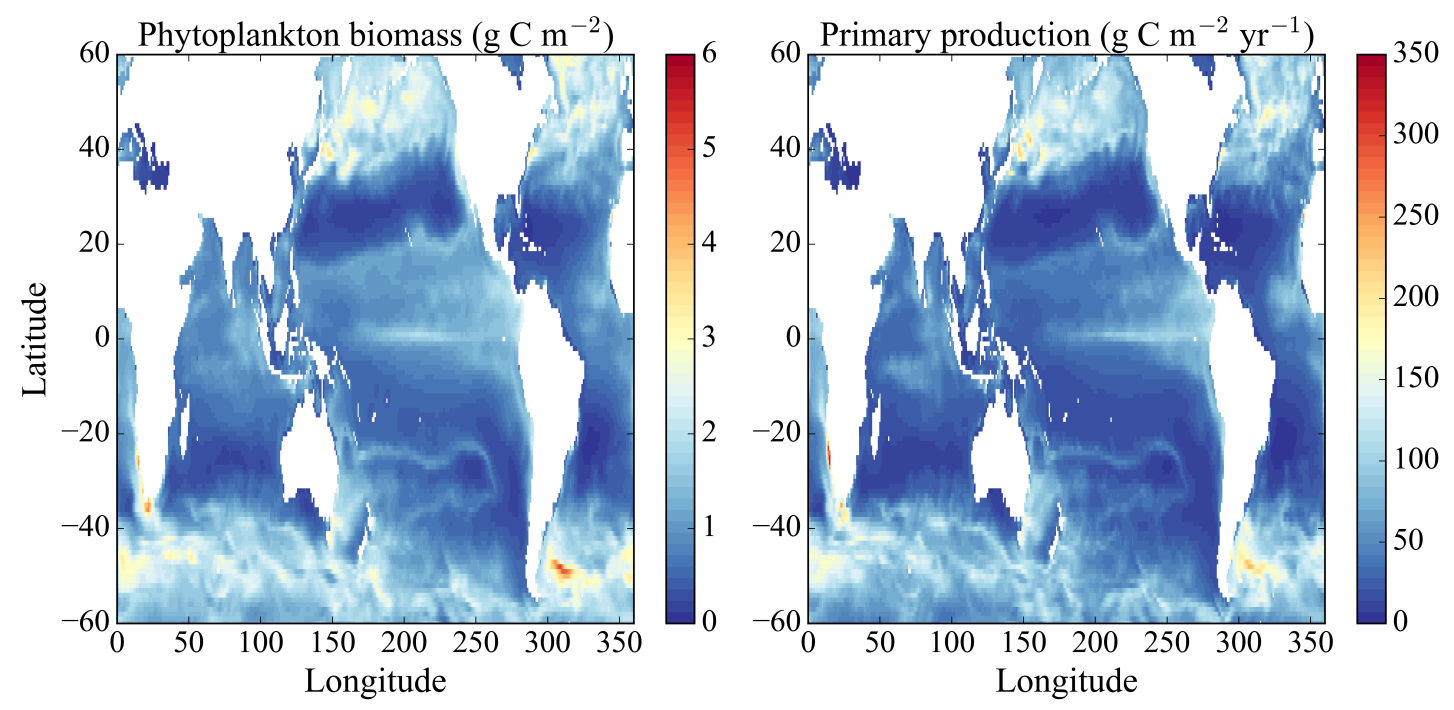

Figure S2. Annual average (a) phytoplankton biomass in $\mathrm{g} \mathrm{C} \mathrm{m}^{-2}$, and (b) annual primary production in $\mathrm{g} \mathrm{C} \mathrm{m}^{-2} \mathrm{y}^{-1}$ in the CR simulation for the 1999 model year. 

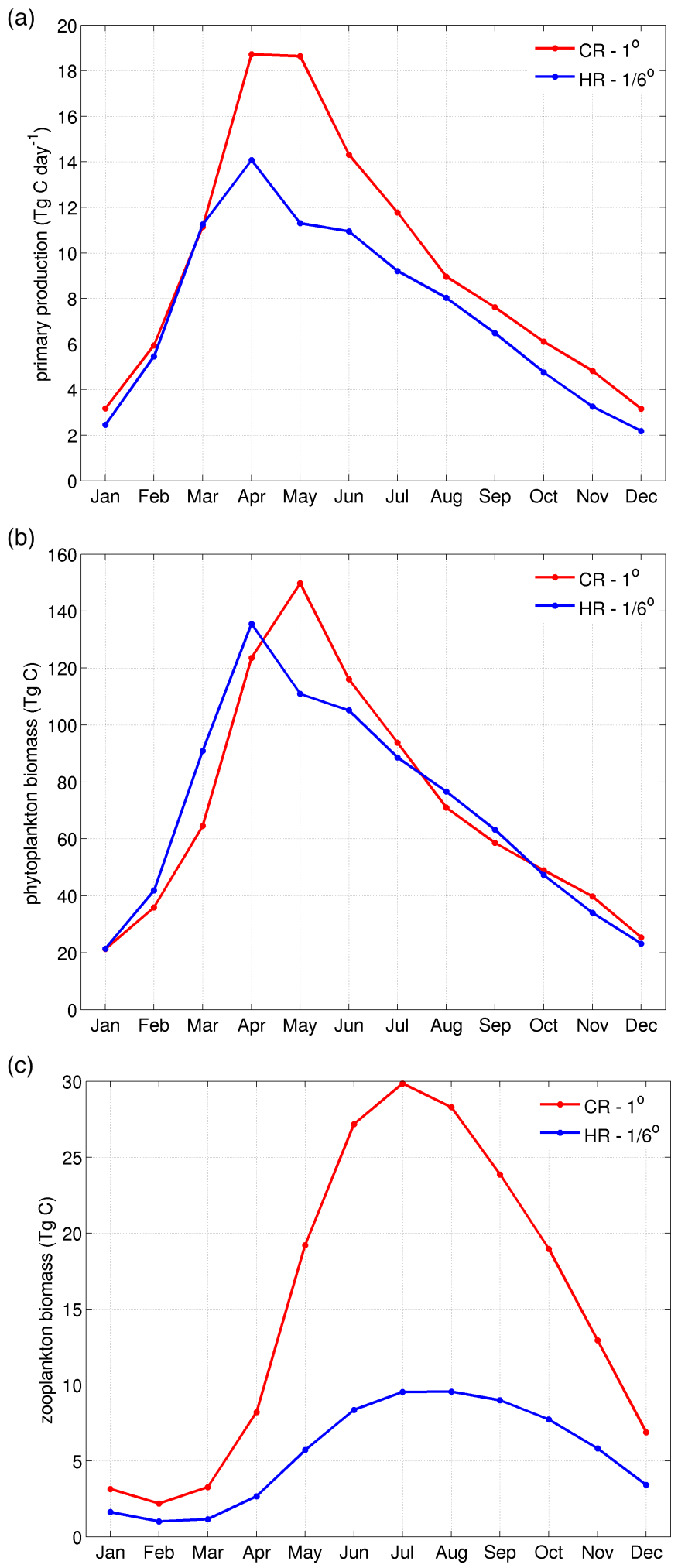

Figure S3. Total monthly integrated (a) primary production, (b) phytoplankton biomass and (c) zooplankton biomass for northern hemisphere ocean regions from $40^{\circ} \mathrm{N}-60^{\circ} \mathrm{N}$. 